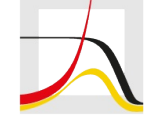

MAX PLANCK INSTITUTE

FOR DEMOGRAPHIC RESEARCH

Konrad-Zuse-Strasse 1 · D-18057 Rostock · Germany · Tel +49 (0) 3812081 - 0 · Fax +49 (0) 3812081 - $202 \cdot$ www.demogr.mpg.de

MPIDR Technical Report TR 2021-001 I May 2021

https://doi.org/10.4054/MPIDR-TR-2021-001

\title{
Additional information for the analysis of optimal vaccination age across countries
}

Héctor Pifarré i Arolas I hector.pifarre@upf.edu

Enrique Acosta I acosta@demogr.mpg.de

Mikko Myrskylä I sekmyrskyla@demogr.mpg.de

For additional material see www.demogr.mpg.de/tr/

(c) Copyright is held by the authors.

Technical reports of the Max Planck Institute for Demographic Research receive only limited review. Views or opinions expressed in technical reports are attributable to the authors and do not necessarily reflect those of the Institute. 


\title{
Additional information for the analysis of optimal vaccination age across countries*
}

\author{
Héctor Pifarré i Arolas ${ }^{\dagger} \quad$ Enrique Acosta ${ }^{\ddagger} \quad$ Mikko Myrskylä ${ }^{\S}$
}

First Draft: March 2021

This Draft: March 29, 2021

Methods and data sources for the manuscript "Optimal vaccination age varies across countries", which elaborates on the findings by Goldstein, Cassidy, and Wachter [1] (henceforth GCW).

\section{Analytical framework}

For given age $x$, the expected years of life lost (eYLL) to COVID-19 is $v_{l}(x)=r(x) \times e(x)$ and $v_{l, \theta}(x)=\theta \times r(x) \times e(x)$ for vaccinated and non-vaccinated individuals, respectively. The protective effect of the vaccine, $\theta \in(0,1)$, is assumed to be age independent; $e(x)$ denotes life expectancy while $r(x)$ the COVID-19 mortality rate. Let $w_{l, \theta}(x)=v_{l}(x)-$ $v_{l, \theta}(x)$ be age $x$ 's eYLL gained from the vaccine. Suppose the goal of vaccination is to minimize eYLL due to COVID-19. This implies that for any age $x$ below the age with the highest mortality rate, $z$ (for most countries $z$ is the oldest age), $r(x)$ must exceed the

\footnotetext{
*The code and data for replication are available at our OSF repository

†enter for Research in Health and Economics, Universitat Pompeu Fabra. Email: hector.pifarredupf.edu

${ }^{*}$ Max Planck Institute for Demographic Research. Email: acosta@demogr.mpg. de

${ }^{\S}$ Max Planck Institute for Demographic Research and Center for Social Data Science, University of Helsinki. Email: myrskyla@demogr.mpg.de
} 
following threshold for $x$ to be given priority over $z$ in vaccination (Condition 1$)$ :

$$
w_{l, \theta}(x) \geq w_{l, \theta}(z) \Longleftrightarrow r^{*}(x) \geq r(z) \times \frac{e(z)}{e(x)}
$$

That is, $r^{*}(x)$ is the COVID-19 mortality rate such that vaccinating $x$ would save as many eYLL as vaccinating $z$. For countries where GCK's result holds, Condition 1 should occur only for the oldest, i.e. (Condition 2):

$$
r^{*}(x) \geq r(z) \times \frac{e(z)}{e(x)} \quad \text { if and only if } x=z
$$

\section{Robustness}

\section{Remaining life expectancy}

Life expectancy at each COVID-19 mortality reporting age group was taken from period single age life tables $[2,3]$, interpolated to the midpoint of the interval. For the open age interval, we assume that the average death from COVID-19 occurs at the following age: we add to the lower bracket of the open interval its remaining life expectancy. Then, interpolated life expectancy values were assigned to that average age of death to identify the remaining years to live at the last age group.

In order to assess the robustness of the results to the assumptions on the open age interval, we construct an upper bound scenario in which we increase $20 \%$ the remaining life expectancy to that age group. Following Condition 1, this results in a higher required mortality rate for relatively young age groups such that they are prioritized in vaccination.

\section{Excess mortality}

As a robustness check for the age structure of confirmed COVID-19 deaths, we estimate excess mortality in 24 countries where weekly all-cause mortality data were available. We 
use the original input data in a standardized format published by the Short-Term Mortality Fluctuations database [2] for most countries, and micro-data of death certificates retrieved from the vital statistics systems in Mexico [4] and Peru [5]. For most countries we include mortality since 2010, except for those in which the data series start later. This is the case of Australia and the US (in 2015); Mexico, Chile, Germany, and Greece (in 2016); and Peru (in 2017). Weekly population at risk between 2010 and 2020 was obtained by interpolating annual population estimates $[2,3]$.

To obtain a mortality baseline, we fit a Generalized Linear Model with Poisson distribution (or Negative binomial when over-dispersion in data was identified) to weekly deaths in each country and age group until 2019. To avoid period shocks from influenza- and heatwaves-related mortality, winter and summer weeks were excluded.

Secular changes in mortality and changes in the population's age structure are controlled by including 3-knot natural splines and the exposures as an offset. The inclusion of a sinusoidal component accounting for mortality seasonality was decided by selecting the best AIC value model. Ninety-five percent prediction intervals were computed using 2000 bootstrap iterations.

Excess mortality is defined as the difference between the observed deaths and the mortality baseline between the 8th week of 2020 and the 2nd week of 2021, including only the weeks where observed mortality was above the upper prediction interval. We group excess mortality estimates using the same age intervals as the reported COVID-19 mortality to compare their age structure.

\section{References}

[1] JR Goldstein, T Cassidy, KW Wachter, Vaccinating the oldest against covid-19 saves both the most lives and most years of life. Proceedings of the National Academy of Sciences 118 (2021). 
[2] Human Mortality Database (2020) Available at www.mortality.org or www. humanmortality.de publisher: University of California, Berkeley (USA), and Max Planck Institute for Demographic Research (Germany).

[3] United Nations, Department of Economic and Social Affairs, Population Division, World population prospects Highlights, 2019 revision Highlights, 2019 revision. (2019) OCLC: 1142478963.

[4] Instituto nacional de estadística, geografía e informática (mexico) (2021) Available at https://www.inegi.org.mx/programas/mortalidad/\#Datos_ abiertos. Accessed 25 March 2021.

[5] Sistema informático nacional de defunciones (peru) (2021) Available at https : / / wWw.minsa.gob.pe/reunis/data/defunciones_registradas.asp. Accessed 25 March 2021. 